\title{
Evolution of Endovascular Therapy in Acute Stroke: Implications of Device Development
}

\author{
Adithya Balasubramaian, Peter Mitchell, Richard Dowling, Bernard Yan \\ Comprehensive Stroke Centre, Royal Melbourne Hospital, Parkville, Victoria, Australia
}

Intravenous thrombolysis is an effective treatment for acute ischaemic stroke. However, vascular recanalization rates remain poor especially in the setting of large artery occlusion. On the other hand, endovascular intra-arterial therapy addresses this issue with superior recanalization rates compared with intravenous thrombolysis. Although previous randomized controlled studies of intra-arterial therapy failed to demonstrate superiority, the failings may be attributed to a combination of inferior intra-arterial devices and suboptimal selection criteria. The recent results of several randomized controlled trials have demonstrated significantly improved outcomes, underpinning the advantage of newer intra-arterial devices and superior recanalization rates, leading to renewed interest in establishing intra-arterial therapy as the gold standard for acute ischaemic stroke. The aim of this review is to outline the history and development of different intra-arterial devices and future directions

Correspondence: Bernard Yan Comprehensive Stroke Centre, Royal Melbourne Hospital Parkville Melbourne, Victoria 3050, Australia Tel: $+61-3-9349-2477$ Fax: +61-3-9349-4489 Email: bernard.yan@mh.org.au@

Received: March 17, 2015

Revised: May 9, 2015

Accepted: May 27, 2015

The authors have no financial conflicts of interest.

in research.

Keywords Mechanical Thrombectomy; Acute Ishemic Stroke; Clot Retrieval; Endovascular; Stentriever

\section{Introduction}

Timely administration $(<4.5$ hours) of intravenous recombinant tissue plasminogen activator (IV rt-PA or tPA) improves outcomes in acute ischemic stroke. ${ }^{1,2}$ However, IV tPA is associated with early recanalization in only $21 \%$ of cases, ${ }^{3}$ with worse rates in distal internal carotid and basilar artery occlusions, and frequent re-occlusions after IV tPA in $12 \% .{ }^{4}$ Furthermore, the narrow time window and strict exclusion criteria limits the opportunity for IV thrombolysis, with a significant proportion of patients found to breach criteria in a recent randomized control trial. ${ }^{2,5}$

Despite the perceived intuitive benefit of endovascular therapy of improved revascularisation and improved outcomes, three major initial randomized control trials- IMS III, ${ }^{6} \mathrm{MR}^{\mathrm{RESCUE}}{ }^{7}$ and SYNTHESIS ${ }^{8}$ could not demonstrate this. However, the negative findings from these studies must be interpreted in the context of several limitations. These include the use of first generation thrombectomy devices and intra-arterial thrombolytic agents to achieve recanalization, ${ }^{9,10}$ suboptimal patient selection due to the lack of sophisticated imaging techniques employed, and lengthy delays to initiation of treatment (mean time to groin puncture 208 minutes in IMS III and 381 minutes in MR RESCUE). 6,7

The development of newer mechanical thrombectomy devices have resulted in superior recanalization in stroke therapy., ${ }^{910}$ In particular, stent retreivers such as Solitiare, TREVO and REVIVE have demonstrated markedly improved recanalization rates compared to their earlier generation counterparts. ${ }^{9-11}$

The incorporation of these devices, improving imaging based patient selection and more expedient treatment times has resulted in positive findings from seven trials, MR CLEAN, ${ }^{12}$ EXTEND-IA, ${ }^{13}$ ESCAPE, ${ }^{14}$ SWIFT PRIME, ${ }^{15}$ REVASCAT, ${ }^{16}$ 
THRACE $^{17}$, and THERAPY, ${ }^{18}$ supporting the superiority of the intra-arterial approach over IV tPA. We aim in this review to outline the history of the development of different intra-arterial devices in this context.

\section{Intra-arterial (IA) thrombolysis}

Advantages of IA thrombolytic therapy over IV therapy include direct infusion of a highly concentrated thrombolytic drug into the occluding thrombus, permitting lower total amounts of systemic concentration of thrombolytic agent to achieve recanalization. ${ }^{19}$ Precise depiction of the arterial anatomy through angiography confers several advantages including the characterization of the obstructive lesion, assessing the extent of collateral circulation, confirmation of degree and timing of recanalization, and providing an option of employing additional mechanical thrombectomy methods to best assist with vessel recanalization. ${ }^{20}$ Conversely, the disadvantages of IA approaches include the need for a specialized neurointerventional team and endovascular facilities, additional time delays required for angiography and microcatheter placement before therapy can be commenced, and the risks of catheter manipulation. ${ }^{20}$

Different agents have been used for the thrombolytic treatment of acute ischaemic stroke. These include tissue plasminogen activator (tPA), urokinase (UK) and pro-urokinase (pro-UK).

\section{Efficacy and safety}

\section{IA Pro-UK}

The Prolyse in Acute Cerebral Thromboembolism (PROACT) trial evaluated the efficacy of IA Pro-Urokinase when administered within 6 hours of stroke onset. ${ }^{21}$ Forty-six patients with angiographically confirmed Thrombolysis in Acute Myocardial Infarction (TIMI) grade 0 or 1occlusion of the M1 or M2 segment of the MCA were randomised into the treatment group (pro-UK and heparin) or placebo group (heparin only) in a 2:1 ratio. Treatment group was associated with superior recanalization compared to the placebo group ( $67 \%$ vs. $18 \%$ TIMI $2-3)$. However the 6 improvement in neurological outcomes, classified as a modified Rankin Scale (mRS) of 0-1, from IAProUK compared to placebo was not significant $(30.8 \%$ vs. $21.4 \%, P=0.72$ ).

PROACT II addressed the shortcomings of its predecessor by using a control group (no IA infusion), and enrolling greater patient numbers. ${ }^{22}$ The definition of a good neurological outcome was also revised to a mRS of 2 or less. Successful recanalization was more commonly seen in the treatment group than in the control group ( $66 \%$ vs. $18 \%, P=0.001)$. Despite similar results regarding clinical outcome to its predecessor (90-day mRS 0-1: $26 \%$ vs. $17 \%, P=0.16$ ), primary efficacy analysis with the revised outcomes showed improved morbidity in patients treated with IA pro-UK (mRS 0-2: 40 vs. $25 \%, P=0.04$ ).

\section{IA-UK}

The Middle Cerebral Artery Embolism Local Fibrinolytic Intervention Trial (MELT) was prematurely aborted due to the approval of IV-rtPA in Japan. ${ }^{23} 114$ ischemic stroke patients presenting within 6 hours of stroke onset, with angiographic occlusions of the M1 or M2 portion of the MCA, were randomised in a 1:1 manner. Recanalization ( $\geq 50 \%$ ) was achieved in 30 (52.7\%) patients. There was no statistical difference in the primary outcome between the UK and control group (mRS 0-2: 49.1\% vs. 38.6\%, $P=0.345)$. However, secondary analyses showed improved functional outcome (mRS 1 or less) in the treatment group compared to the control group ( $42.1 \%$ vs. $22.8 \%, P=0.017)$. When compared to the PROACT trials, ${ }^{21,22}$ randomized patients in this study had lower baseline NIHSS scores, possibly contributing to the improved outcomes in the control group.

\section{Combined IV and IA tPA}

Several studies have been conducted to investigate the efficacy of IV and IA tPA. The Emergency Management of Stroke (EMS) trial, a double-blinded, randomized, placebo-controlled multicentre trial, aimed to investigate the feasibility and safety of a combined IV and IA approach to 7 thrombolysis. ${ }^{24}$ Thirty-five patients presenting within 3 hours of symptom onset were randomised into either the IV/IA group $(n=17)$ or placebo/IA group $(n=18)$. The primary outcome was defined as 7 point or greater improvement in the National Institutes of Health Stroke Scale (NIHSS) or a score of 0 or 1 at 7 days. Successful recanalization was demonstrated to be superior in the IV/IA treatment group (55\% vs. $10 \%, P=0.05) .{ }^{24}$ Despite superior recanalization rates, there was no difference in neurological outcome- $24 \%$ in both groups. A lack of improvement in clinical outcome may be attributed to limited patient numbers, a high rate of adverse events in the IV/IA tPA group unrelated to treatment, and poor randomisation of stroke severity.

Using historical controls from the National Institute of Neurological Disorders and Stroke (NINDS) trial of IV tPA, IMS-II aimed to evaluate the effectiveness and safety of combined IV/ IA therapy. Whenever possible, an EKOS micro-infusion catheter (EKOS Corporation Bothell, Washington, USA) was used in vessel-appropriate lesions to alter the structure of the thrombus and facilitate access of the thrombolytic agent to potentially accelerate thrombolysis. ${ }^{25}$ The 81 subjects enrolled into the IMS II study were also compared with the rt-PA and placebo-treated 
subjects from the NINDS study. Successful recanalization was achieved in $60 \%$ of patients (TIMI 2-3) with $4 \%$ achieving complete recanalization (TIMI 3). IMS II subjects had significantly better outcomes at 3 months than NINDS placebo-treated subjects (mRS 0-2: $46 \%$ vs. $28 \%$ ), but not NINDS IV tPA treated subjects (mRS 0-2: $46 \%$ vs. $39 \%$ ).

The RECANALISE study prospectively examined 53 patients who were treated with IV and IA Alteplase within 3 hours experiencing symptoms consistent with an acute ischemic stroke. ${ }^{26} \mathrm{Re}-$ canalization (TIMI 2-3), good neurological outcome (mRS 0-2) and the rates of symptomatic ICH were compared with $107 \mathrm{pa}-$ tients previously treated with IV Alteplase alone. Patients in the treatment group received additional mechanical thrombectomy if recanalization was not achieved after IA Alteplase administration. Despite significantly higher recanalization rates in the treatment group of the RECANALISE trial ( $87 \%$ vs. $52 \%, P<0.01$ ), no significant difference in 90 day neurological outcome was found between patients treated using a combined IV-endovascular approach over those managed with IV tPA alone (57\% vs. $44 \%$, $P=0.13)$. Several limitations were identified in the RECANALISE trial. The sample population was a small one, with the possibility of selection bias. Additionally, a lack of catheter angiography in the control group resulted in heterogeneous methods for measuring recanalization.

\section{Summary}

Recanalization ( $\geq 50 \%$ or TIMI $2-3$ ) was achieved in $47-80 \%$ of patients receiving IA thrombolysis. ${ }^{21-26}$ Good neurological outcome at 90 days (mRS 0-2) was found in 40-57\% ${ }^{21-23,25,26} \mathrm{In}$ tra-arterial thrombolysis was not shown to be significantly associated with greater symptomatic haemorrhagic transformation, with rates of 9-15.4\% across all agents. ${ }^{21-26}$

The multitude of different intra-arterial thrombolytic agents available have been shown to offer promising clinical outcome in selected patients with acute ischaemic stroke without a significant increase in haemorrhagic complications. However, there is no level 1 evidence whether intra-arterial thrombolysis alone confers outcome benefit over IV tPA therapy.

\section{Mechanical thrombectomy}

Mechanical thrombectomy devices are divided into 2 major groups based on their mechanism of action: those that use an approach distal (retrievers) or proximal to thrombi (aspiration devices).

\section{Retrievers}

The Mechanical Embolus Removal in Cerebral Ischemia (MERCI, Concentric Medical, California, USA) was the first stroke mechanical thrombectomy device approved by the FDA in 2004 (Figure 1A). The MERCI is a flexible corkscrew-shaped device constructed of nitinol memory-wire, designed to remove blood clots from the brain in patients with ischaemic stroke. ${ }^{27}$

A number of other specifically directed thrombectomy devices
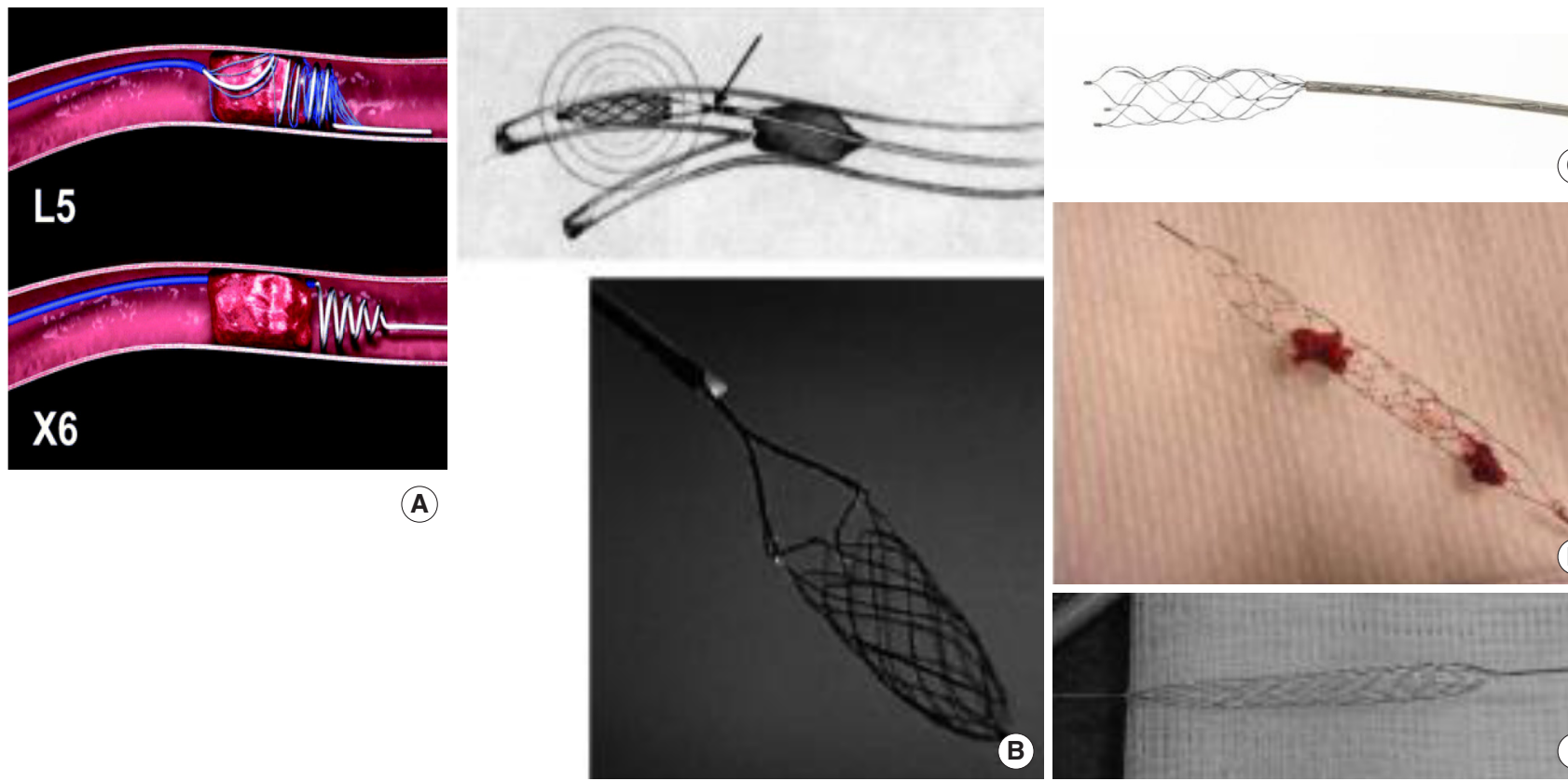

(C)
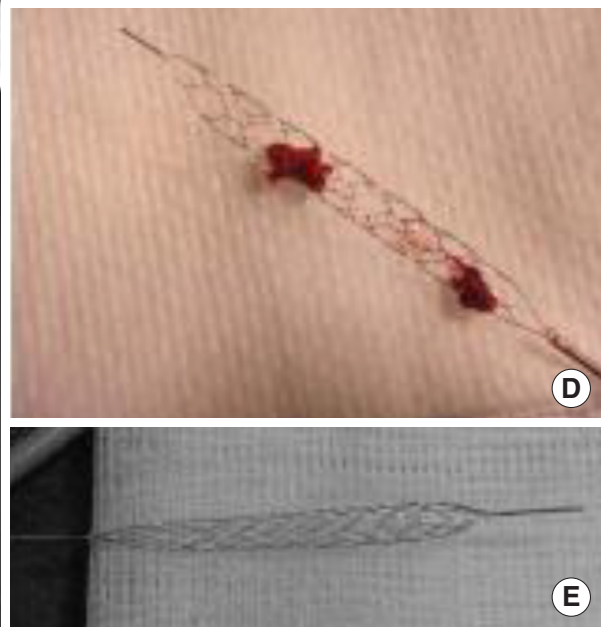

Figure 1. (A) MERCl device. ${ }^{27}$ Available in the public domain: http://stroke.ahajournals.org/content/39/4/1205.figures-only. (B) CATCH device. ${ }^{28}$ Available in the public domain: http://www.ajnr.org/content/32/8/1381/F1.expansion.html. (C) SOLITAIRE device. ${ }^{29}$ Available in the public domain: http://www.covidien.com/imageServer.aspx/doc245416.pdf?contentID=31741\& contenttype= application/pdf. (D) TREV0 device..$^{32}$ Available in the public domain: http://stroke.ahajournals.org/content/43/6/1657/F1.expansion.html. (E) REVIVE device. ${ }^{11}$ Available in the public domain: http://stroke.ahajournals.org/content/42/10/2954.figures-only. 
with various designs were subsequently developed. The $\mathrm{CATCH}$ device (Balt Extrusion, Montmorency, France) also employs a self-expanding Nitinol basket to retrieval thrombi using a distal $\operatorname{approach}($ Figure $1 \mathrm{~B}){ }^{28}$

The Solitaire FR (Ev3, California, USA) was approved by the FDA in 2012 (Figure 1C) ${ }^{29}$ Solitaire FR comprises a stentriever, a retrievable stent-like device that is designed to act as retriever. It promotes restoration of blood flow by providing radial force to open and restore occluded vessels, administer adjunctive medical therapy and retrieve clots via an open-ended basket. ${ }^{30,31}$

Other recent stentrievers devices include the TREVO device (Concentric Medical, California, USA; Figure 1D) ) $^{10,32}$ and the REVIVE system (Codman \& Shurtleff Inc, Massachusetts, USA; Figure 1E).$^{11}$ Both the TREVO and REVIVE stentrievers employ a closed distal end of the stent to prevent clot embolization. However, the TREVO device's stent wires are radio-opaque, allowing better visibility during angiography, compared to the REVIVE system.

\section{Aspiration devices}

Several aspiration techniques have also been developed for acute ischaemic stroke treatment, including the Penumbra System (Penumbra Inc, California, USA). ${ }^{33}$ The Penumbra system is composed of 3 main components: a reperfusion catheter, separator, and thrombus removal ring (Figure 2). This device removes the thrombus through 2 mechanisms: aspiration and extraction. Aspiration is achieved when the separator is gently pulled back and forth into the reperfusion catheter resulting in fragmentation with subsequent aspiration of the fragments when the reperfusion catheter is connected to a suction device. If residual thrombus remains after revascularization with aspiration, the thrombus removal ring is then used to directly engage and remove the thrombus.

In a similar vein, the QuickCat (DSM Inc, Philadelphia, USA) and PRONTO (Vascular Solutions Inc, Minnesota, USA) extraction devices are both monorail catheters which aspirate clot through negative pressure created by a connected 3 way stopcock. ${ }^{34}$ However, there is insufficient data for their use in acute stroke.

\section{Efficacy and safety}

Please refer to Table 1 for summary of devices.

\section{MERCI}

The Multi MERCI trial, an international, multicenter prospective study, enrolled 177 patients to evaluate the combined safety and efficacy of IV tPA with the MERCI device when used within 8 hours of stroke onset. ${ }^{27}$ Recanalization was assessed as TIMI score 2-3, and a good neurological outcome was defined as a 90 day $\mathrm{mRS}$ score of 0-2. 131 patients received mechanical thrombectomy with successful recanalization (TIMI 2-3) achieved in $57.3 \%$ of patients and $68.5 \%$ of patients after adjunctive therapy (IA-tPA). Thirty-six percent of patients in this study had favourable neurological outcomes.

The rate of symptomatic haemorrhage observed in the MultiMERCI trial was similar to that found with other modes of intraarterial interventions (10\%).

\section{$\mathrm{CATCH}$}

The efficacy of the CATCH device was evaluated in a retrospective study of 40 patients presenting with anterior or posterior circulation strokes. ${ }^{28}$

Recanalization (TIMI 2-3) was achieved in $65 \%$ of the population, with half of these patients achieving full (TIMI 3) recanalization. A good neurological outcome (90 day mRS 0-2) was achieved in 14 patients (39\%). These outcomes were deemed to be comparable to those achieved in the Multi MERCI trial. ${ }^{27}$

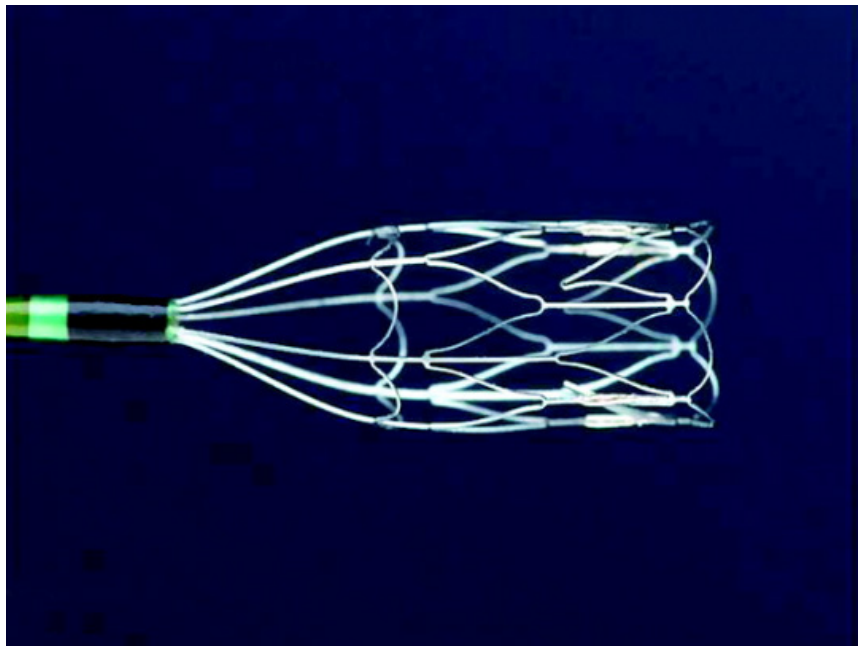

Figure 2. Penumbra device. ${ }^{33}$ Available in the public domain: http://www.ajnr.org/content/29/7/1409/F1.expansion.html. 
Table 1. Endovascular device advantages and disadvantages and trial results

\begin{tabular}{|c|c|c|c|c|c|c|}
\hline Endovascular device & Study & Recanalization success (\%) & Clinical outcome & $\begin{array}{l}\text { Symptomatic } \\
\text { haemorrhage }\end{array}$ & Advantages & Disadvantages \\
\hline \multirow{2}{*}{$\begin{array}{l}\text { Microcatheter infusion } \\
\text { of Prourokinase }\end{array}$} & PROACT $^{21}$ & TIMI 2-3, 67\% & 90 day mRS $0-1,30.8 \%$ & $15.4 \%$ & Easy Navigation & Prolonged Infusion \\
\hline & PROACT $\|^{22}$ & TIMI 2-3, 66\% & $\begin{array}{l}90 \text { day } m R S 0-1,26 \% \\
90 \text { day } m R S 0-2,40 \%\end{array}$ & $10 \%$ & & \\
\hline \multirow{2}{*}{$\begin{array}{l}\text { Microcatheter infusion } \\
\text { of Urokinase }\end{array}$} & $\mathrm{MELT}^{23}$ & Complete, 5.3\% & 90 day mRS $0-2,49.1 \%$ & $9 \%$ & Easy Navigation & Prolonged Infusion \\
\hline & & Partial $\geq 50 \%, 47.4 \%$ & & & & \\
\hline \multirow{3}{*}{$\begin{array}{l}\text { Microcatheter infusion } \\
\text { of tissue plasminogen } \\
\text { activator }\end{array}$} & $\mathrm{EMS}^{24}$ & TIMI 2-3, 55\% & $\begin{array}{l}\text { NIHSS 0-1 or } \geq 7 \text { point } \\
\text { improvement, } 24 \% \text { at } 7 \text { days }\end{array}$ & $11.8 \%$ & Easy Navigation & Prolonged Infusion \\
\hline & $\mid \mathrm{MS} \|^{25}$ & TIMI 2-3, 60\% & $\begin{array}{l}90 \text { day } m \mathrm{mRS} 0-1,33 \% \\
90 \text { day } \mathrm{mRS} 0-2,46 \%\end{array}$ & $9.9 \%$ & & \\
\hline & RECANALISE ${ }^{26}$ & TIMI 2-3, 87\% & 90 day mRS $0-2,57 \%$ & $9 \%$ & & \\
\hline \multirow[t]{2}{*}{ MERCI retriever } & Multi MERCl' ${ }^{27}$ & $\begin{array}{l}\text { TIMI 2-3, 57.3\% with } \\
\text { MERCI alone }\end{array}$ & 90 day $m R S 0-2,36 \%$ & $10 \%$ & $\begin{array}{l}\text { Improved recanalization } \\
\text { compared to IV and } \\
\text { IA thrombolysis }\end{array}$ & $\begin{array}{l}\text { May require multiple } \\
\text { passes of device to } \\
\text { achieve recanalization }\end{array}$ \\
\hline & & $\begin{array}{l}\text { TIMI 2-3, 68.5\% with } \\
\text { adjunctive IA therapy }\end{array}$ & & & $\begin{array}{l}\text { Can be used when } \\
\text { thrombolysis } \\
\text { contraindicated }\end{array}$ & $\begin{array}{l}\text { Steep operator } \\
\text { learning curve }\end{array}$ \\
\hline \multirow[t]{2}{*}{ CATCH device } & Mourand et al ${ }^{28}$ & TIMI 2-3, 65\% & 90 day $m R S 0-2,39 \%$ & $18 \%$ & $\begin{array}{l}\text { Improved recanalization } \\
\text { compared to IV and } \\
\text { IA thrombolysis }\end{array}$ & $\begin{array}{l}\text { May require multiple } \\
\text { passes of device to } \\
\text { achieve recanalization }\end{array}$ \\
\hline & & & & & $\begin{array}{l}\text { Can be used when } \\
\text { thrombolysis } \\
\text { contraindicated }\end{array}$ & $\begin{array}{l}\text { Steep operator } \\
\text { learning curve }\end{array}$ \\
\hline SOLITAIRE stentriever & $\mathrm{SWIFT}^{9}$ & TIMI 2-3,61\% & 90 day mRS $0-2,58 \%$ & $2 \%$ & $\begin{array}{l}\text { Thrombectomy approach } \\
\text { allowing faster and } \\
\text { greater recanalization rates }\end{array}$ & $\begin{array}{l}\text { Less steep operator } \\
\text { learning curve }\end{array}$ \\
\hline \multirow[t]{3}{*}{ TREVO stentriever } & TREV0 ${ }^{32}$ & $\begin{array}{l}\text { TICI 2b-3, 73.3\% with } \\
\text { TREVO alone }\end{array}$ & 90 day mRS $0-2,45 \%$ & $11.7 \%$ & $\begin{array}{l}\text { Thrombectomy approach } \\
\text { allowing faster and } \\
\text { greater recanalization rates }\end{array}$ & $\begin{array}{l}\text { Less steep operator } \\
\text { learning curve }\end{array}$ \\
\hline & & $\begin{array}{l}\text { TICI 2b-3, 86.7\% with } \\
\text { adjunctive IA therapy }\end{array}$ & & & & \\
\hline & TREVO $2^{10}$ & TICI 2a-3, 86\% & 90 day mRS $0-2,40 \%$ & $7 \%$ & & \\
\hline \multirow[t]{2}{*}{ REVIVE stentriever } & Rohde et a $1^{11}$ & TICl 2b-3, 100\% & $\begin{array}{l}\text { NIHSS } 0-1 \text { or }>8 \text { point } \\
\text { improvement, } 60 \% \text { at } 30 \text { days }\end{array}$ & $20 \%$ & $\begin{array}{l}\text { Thrombectomy approach } \\
\text { allowing faster and } \\
\text { greater recanalization rates }\end{array}$ & $\begin{array}{l}\text { Less steep operator } \\
\text { learning curve }\end{array}$ \\
\hline & & & & & $\begin{array}{l}\text { Closed basket at end of } \\
\text { stent designed to prevent } \\
\text { clot embolization }\end{array}$ & \\
\hline \multirow[t]{3}{*}{$\begin{array}{l}\text { PENUMBRA aspiration } \\
\text { device }\end{array}$} & PIVOTAL $^{37}$ & TIMI 2-3, 81\% & 90 day mRS $0-2,25 \%$ & $11 \%$ & $\begin{array}{l}\text { Multimodal approach that } \\
\text { allows rapid aspiration } \\
\text { and subsequent } \\
\text { thrombectomy of } \\
\text { fragmented thrombus }\end{array}$ & $\begin{array}{l}\text { Less steep operator } \\
\text { learning curve }\end{array}$ \\
\hline & $\mathrm{POST}^{38}$ & TIMI 2-3, 87\% & 90 day mRS $0-2,41 \%$ & $6 \%$ & & \\
\hline & SPEED ${ }^{36}$ & TIMI 2-3, 91\% & 90 day mRS $0-2,34 \%$ & $14 \%$ & & \\
\hline
\end{tabular}

However, the rates of symptomatic haemorrhage were much higher using the $\mathrm{CATCH}$ device $(18 \%) .{ }^{28}$ Being a retrospective trial, there were several limitations to the study design. There was significant heterogeneity in adjunctive treatment. 36 (90\%) patients received additional $\mathrm{r}$-tPA. Other interventions included thromboaspiration, angioplasty, and stent placement in addition to $\mathrm{CATCH}$ thrombectomy.

\section{Solitaire}

The Solitaire With Intention For Thrombectomy (SWIFT) randomized clinical trial assigned 113 stroke patients who presented within 8 hours of symptom onset at 18 hospitals to either the Solitaire FR group $(\mathrm{n}=58)$ or the Merci Retriever device group $(\mathrm{n}=55){ }^{.}$

The SWIFT study observed a significantly higher recanalization rate (TIMI score 2-3) obtained with the Solitaire device 
compared to the MERCI ( $61 \%$ vs. $24 \%, P<0.0001)$ and a more favourable 3 -month neurological outcome ( $58 \%$ vs. $33 \%, P=$ $0.0001)$ without increasing rates of symptomatic haemorrhagic transformation (2\% vs. $11 \%)^{9}$

\section{TREVO}

The efficacy and safety of the TREVO device was first evaluated through a prospective, single-center study of 60 patients anterior or posterior circulation strokes. ${ }^{32}$ Successful revascularisation (Thrombolysis in Cerebral Infarction 2b-3) was obtained in $44(73.3 \%)$ of cases when only the TREVO device was used and in 52 (86.7\%) when other devices or additional intra-arterial tPA were also required. Good clinical outcome (mRS 0-2) was achieved in 27 (45\%) of patients and the mortality rate was $28.3 \% .^{32}$

The TREVO 2 trial- a randomized control trial conducted across centers in the USA and Spainassessed the efficacy of the TREVO device compared to MERCI. ${ }^{10}$ Patients who had large vessel anterior circulation strokes were randomized to receive thrombectomy using either the TREVO or MERCI device ( 88 vs. 90 patients respectively). Significant improvements were demonstrated with the TREVO device for revascularisation (TICI 2a-3: $86 \%$ vs. $60 \%, P<0.01)$ and clinical outcome (90 day mRS $0-2: 40 \%$ vs. $22 \%, P=0.01)$.

Seven $(11.7 \%)$ patients in the TREVO study experienced symptomatic intracranial haemorrhage. ${ }^{32}$ More extensive enquiry into the safety profile of the TREVO device was conducted in the TREVO 2 trial. ${ }^{10}$ No significant difference was found for the outcome of composite adverse events (15\% vs. $23 \%$, $P=0.23)$ and symptomatic ICH (7\% vs. $9 \%, P=0.78)$ between the TREVO and MERCI devices respectively. However, it was noted that vessel perforations were 10 times more common using the MERCI device ( $1 \%$ vs. $10 \%, P=0.02$ ).

\section{REVIVE}

The REVIVE device was evaluated in a single center study, which enrolled 10 patients with acute large vessel occlusions into a study ${ }^{11}$ Recanalization success as assessed using the Thrombolysis in Cerebral Infarction (TICI) score was achieved in $100 \%$ of patients without device-related complications. ${ }^{11,35} \mathrm{Clini}-$ cal outcome was then assessed at 30 days post intervention using the National Institute of Health Stroke Scale (NIHSS) with 60\% of patients achieving a clinical improvement of $>8$ points or NIHSS of 0-1. Symptomatic intracranial haemorrhage occurred in $20 \%$ of patients. ${ }^{11}$

\section{Penumbra}

The Penumbra Pivotal Stroke Trial, the Penumbra POST study, and recently the SPEED study have evaluated the safety and effectiveness of the Penumbra system. ${ }^{36-38}$ The Penumbra Pivotal Stroke Trial $(\mathrm{n}=125)$ and POST study $(\mathrm{n}=157)$ evaluated patients with stroke symptom onset within 8 hours and NIHSS $\geq 8$, whilst the SPEED study $(n=87)$ examined cases with angiographic evidence of large vessel occlusion..$^{36-38}$ Eighty one percent of patients from the Penumbra Pivotal Stroke trial, 87\% from the Penumbra POST study, and 91\% from the SPEED study achieved successful recanalization (TIMI 2-3) with $25 \%$, $41 \%$ and $34 \%$ achieving good clinical outcome (mRS 0-2 at 90 days) respectively. ${ }^{36-38}$ Eleven percent from the Pivotal Trial, 6\% in the POST study and 14\% in the SPEED study experienced symptomatic intracranial haemorrhage. ${ }^{36-38}$

\section{Summary}

Recanalization (TIMI 2-3 or TICI 2b-3) was achieved in 24$100 \%$ of patients and good clinical outcome (mRS 0-2, NIHSS score $0-1$ or NIHSS improvement of $>8$ points) noted in 22 $60 \% .^{9-11,27,28,32,36-38}$ The rates of symptomatic haemorrhagic transformation were found to be between 6-20\% across all devices.

\section{A new dawn for stroke therapy}

The MR CLEAN (Multicenter Randomized CLinical trial of Endovascular treatment for Acute ischemic stroke in the Netherlands) study was a landmark trial and the first RCT to demonstrate the superiority of intra-arterial treatment. ${ }^{12}$ Five hundred patients across 17 centers in the Netherlands who presented with clinical and radiological evidence of a proximal anterior circulation stroke within 6 hours of onset were randomized to receive intra-arterial therapy with standard care versus standard care alone. ${ }^{12}$ The intervention group received chemical and/or mechanical endovascular therapy. Intra-arterial thrombolysis was achieved using alteplase and urokinase, whilst mechanical treatment involved thrombectomy, aspiration or stenting according to neurointerventionist preference.

The primary outcome was based on 90 day mRS score, which showed a significant improvement in outcomes for patients receiving intra-arterial therapy (adjusted odds ratio 1.67, 95\% Confidence Interval 1.21-2.30). This benefit was conferred to all prespecified dichotomisations of the $\mathrm{mRS}$ except death 12 . The incidence of functional independence, defined as mRS 0-2, was also greater in this population by $13.5 \%$ (32.6\% vs. $19.1 \%) 12$. Secondary outcomes including clinical (NIHSS score after 5-7 days), radiological (TICI $2 \mathrm{~b}$ or 3 ), and safety (adverse events) all favoured the intervention group.

Compared to the previous three negative randomized control trials examining the efficacy of IA therapy, MR CLEAN had sev- 
eral advantages. It benefitted from the increased availability of CTA to confirm the presence of proximal anterior circulation occlusion, allowing its use in the inclusion criteria. $82 \%$ of all patients in the intervention group also were subject to intervention using stent retrievers, which have been demonstrated to be superior to first generation devices. Limitations include a broad inclusion criteria, including patients with characteristics that would confer poor baseline prognosis. This included those who had contraindications or non responders to IV tPA. Nonetheless, the trial was the first to offer compelling evidence for intra-arterial therapy to be used as a first line standard of care when patients with anterior circulation strokes present within 6 hours. Numerous subsequent trials were terminated prematurely for this reason. Please refer to Table 2 for summary of randomized control trials.

The EXTEND-IA (Extending the Time for Thrombolysis in Emergency Neurological Deficits - Intra-Arterial) randomized control trial confirmed the positive findings from MR CLEAN, and underlined the importance of prudent imaging based selection to maximise the efficacy of endovascular stroke therapy. ${ }^{13}$ Patients with ICA or MCA occlusions within 4.5 hours of onset, CT evidence of perfusion mismatch and core infarct volume of less than $70 \mathrm{~mL}$ were randomized to receive mechanical thrombectomy with the Solitaire device after IV tPA vs tPA alone. Endovascular therapy had to be commenced within 6 hours of stroke onset.

The trial had to be stopped after randomisation of 70 patients in a 1:1 manner. Endovascular therapy demonstrated significantly superior rates of early neurological improvement at 3 days ( $80 \%$ vs. $37 \%$ ), and functional independence at 90 days ( $\mathrm{mRS}$
$0-271 \%$ vs. $40 \%) .{ }^{13}$ The safety profile of patients in the endovascular treatment was also validated, with no significant differences in the rates of death or symptomatic ICH.

The imaging guided approach to identifying patients who would benefit from reperfusion therapy allowed more expedient randomisation and thus time to intervention. The high rates of revascularisation (TIMI 2-3 86\%) compared to previous trials could be attributed to the sole use of the Solitaire FR stent retriever, previously shown to have superior outcomes compared to first generation devices used in initial trials. ${ }^{9,13}$ Limitations include the small population number. This may have therapeutic implications given the strict inclusion criteria- more than 7,798 patients were screened-and possibly overestimate treatment effect.

Concurrently released and published with EXTEND-IA, the ESCAPE (Endovascular Treatment for Small Core and Anterior Circulation Proximal Occlusion With Emphasis on Minimizing CT to Recanalization Times) trial also highlighted the efficacy of endovascular therapy in patients using CT guided patient selection within 12 hours of stroke onset. ${ }^{14}$ Three hundred Sixteen patients with CT Angiography evidence of proximal artery occlusion with good collateralisation and small infarct core using an ASPECTS (Alberta Stroke Program Early Computed Tomography Score) of 6 to 10, were randomized to receive medical management versus rapid endovascular treatment predominantly using stent retrievers, within 60 minutes. ${ }^{14,39}$ Both arms received IV tPA if patients presented within 4.5 hours.

One hundred Sixty-five patients were randomized to the intervention arm and were noted to have a superior primary outcome of functional independence (90 day mRS score of 0-2

Table 2. Randomized control trials of endovascular therapy

\begin{tabular}{|c|c|c|c|c|}
\hline Randomized control trials & Recanalization success (\%) & Devices & Clinical outcome & Symptomatic haemorrhage \\
\hline IMS $\|\left.\right|^{6}$ & $\begin{array}{l}\text { TICI 2-3, 81\% for ICA } \\
\text { occlusions, 86\% for M1, 88\% M2 }\end{array}$ & $\begin{array}{l}\text { Mixed (Microcatheter infusion of } \\
\text { IA tPA 49.1\%, MERCI 28.4\%, } \\
\text { Penumbra 16.2\%, Solitaire 1.5\%) }\end{array}$ & $\begin{array}{l}90 \text { day mRS 0-2, 40.8\% (vs. 38.7\% with } \\
\text { IV tPA, age adjusted absolute } \\
\text { difference } 1.5 \%, 95 \% \text { Cl 6.1-9.1\%) }\end{array}$ & $6.2 \%$ \\
\hline SYNTHESIS ${ }^{8}$ & & Mixed & $\begin{array}{l}90 \text { day mRS } 0-1,30.4 \% \text { (vs. } 34.8 \% \text { with } \\
\text { IV tPA, adjusted OR 0.71, } P=0.16 \text { ) }\end{array}$ & $10 \%$ \\
\hline MR RESCUE $^{\top}$ & TICI 2a-3, 67\% & $\begin{array}{l}\text { Mixed (MERCl alone } 60.7 \% \text {, Penumbra } \\
\text { alone } 23 \% \text {, both devices } 16.4 \% \text { ) }\end{array}$ & $\begin{array}{l}90 \text { day mRS mean, } 3.9 \text { (vs. } 3.9 \text { with } \\
\text { standard care, } P=0.99 \text { ) }\end{array}$ & $4.7 \%$ \\
\hline MR CLEAN ${ }^{12}$ & $\mathrm{TICl} 2 \mathrm{~b}-3,58.7 \%$ & $\begin{array}{l}\text { Mixed (Microcatheter infusion of } \\
\text { IA tPA, MERCI, Penumbra, Solitaire }\end{array}$ & $\begin{array}{l}90 \text { day mRS 0-2, 32.6\% (vs. 19.1\% with } \\
\text { standard care, adjusted OR 2.16, } \\
95 \% \mathrm{Cl} 1.39-3.38 \text { ) }\end{array}$ & $7.7 \%$ \\
\hline EXTEND-IA ${ }^{13}$ & TIMI 2-3, 89\% & Solitaire & $\begin{array}{l}90 \text { day mRS } 0-2,71 \% \text { (vs. 40\% with } \\
\text { IV tPA, adjusted OR 4.2, } 95 \% \text { Cl 1.4-12) }\end{array}$ & $0 \%$ \\
\hline ESCAPE $^{14}$ & $\mathrm{TICl} 2 \mathrm{~b}-3,72.4 \%$ & Mixed (Solitaire in 77\%) & $\begin{array}{l}90 \text { day mRS } 0-2,53 \% \text { (vs. } 29.3 \% \text { with } \\
\text { standard care, adjusted OR 1.7, } \\
95 \% \mathrm{Cl} 1.3-2.2 \text { ) }\end{array}$ & $3.6 \%$ \\
\hline SWIFTPRIME $^{15}$ & TICl 2b-3, 88\% & Solitaire & $\begin{array}{c}90 \text { day mRS } 0-2,60 \% \text { (vs. 35\% with } \\
\text { IV tPA, OR } 1.7,95 \% \text { Cl 1.23- } 2.33 \text { ) }\end{array}$ & $3 \%$ \\
\hline REVASCAT $^{16}$ & $\mathrm{TICl} 2 \mathrm{~b}-3,65.7 \%$ & Solitaire & $\begin{array}{l}90 \text { day mRS } 0-2,43.7 \% \text { (vs. } 28.2 \% \text { with } \\
\text { standard care, adjusted OR 1.2, } \\
95 \% \mathrm{Cl} 1.1-4 \text { ) }\end{array}$ & $1.9 \%$ \\
\hline
\end{tabular}


$53.0 \%$ vs. $29.3 \%$ in the control group), with an associated reduction in mortality ( $10.4 \%$ vs. $19.0 \%)$ and no significant difference in adverse events. ${ }^{14}$

Given analysis of previous trials illustrating the importance of time to reperfusion, there was a strong emphasis on delivering rapid endovascular therapy, with a median time of 84 minutes from noncontrast $\mathrm{CT}$ to first reperfusion. The superior rates of recanalization compared to MR CLEAN (TICI $2 b$ to $372.4 \%$ ) could be attributed to this. ${ }^{12,14}$ These patients were predominantly treated at centers with significant experience in endovascular management and sophisticated imaging, allowing expedient treatment from stroke onset. This may impact the generalizability of results.

Presented at the 2015 International Stroke Conference with EXTEND-IA and ESCAPE, the SWIFT PRIME ("Solitaire ${ }^{\text {Tw }}$ FR as Primary Treatment for Acute Ischemic Stroke") study's results also demonstrated the efficacy of endovascular therapy using the Solitaire device. ${ }^{15} 196$ patients with evidence of a small-moderate core infarct, defined as an ASPECTS score of $>6$, were randomised to either receive combined IV tPA and endovascular therapy with the Solitaire device within 6 hours of anterior circulation stroke onset vs IV tPA alone. Primary outcomes included 3 month neurological outcome and recanalization rates. ${ }^{40}$

Patients who received endovascular therapy with IV tPA were again found to have unequivocally higher rates of 90 day functional independence (mRS 0-2: 60\% vs. $35 \%, P<0.001$ ) compared to the control group, without any significant difference in mortality or adverse outcomes. Notably, $88 \%$ of patients had successful reperfusion (TICI 2b-3) immediately post intervention, which could be attributed to a high proportion of occlusions in the M1 segment (67\%), and the sole use of the Solitaire device. This may impact generalizability of results, particularly with regards to $\mathrm{M} 2$ and ICA occlusions.

The REVASCAT (Endovascular Revascularization With Solitaire Device Versus Best Medical Therapy in Anterior Circulation Stroke Within 8 hours) trial was also published simultaneously with SWIFT PRIME, highlighting the efficacy using the Solitaire device for proximal anterior circulation stroke within 8 hours of onset. ${ }^{16} 206$ patients across 4 hospitals in were randomized in a 1:1 ratio between the treatment and control groups. Patients with a large infarct core, defined as ASPECT scores of $<7$ and $<6$ on non-contrast CT and MRI DWI respectively, were excluded from the study. Recanalization (TICI 2b-3) was achieved in $65.7 \%$ of patients. Treatment with thrombectomy was again found to be superior for restoring functional independence compared to standard medical therapy (90 day mRS 0-2: $43.7 \%$ vs. $28.2 \%$ in the control group), with a similar safety profile.

The inferior rates of functional independence compared to
EXTEND IA, ESCAPE, and SWIFT PRIME may be in part due to the use of ASPECTS scoring criteria, which is less accurate than diffusion imaging for the estimation of infarct core volume, and longer times from stroke onset to reperfusion. Two further studies- THERAPY and THRACE- were concurrently presented with REVASCAT at the 2015 European Stroke Organisation conference. ${ }^{17,18}$ THRACE randomised 414 patients across 26 centres in France, who presented within 5 hours of symptom onset with either anterior or posterior large artery occlusions, to receive mechanical thrombectomy after. IV tPA vs IV tPA alone. Preliminary results suggested a significant benefit in 90 day functional independence ( $\mathrm{mRS} 0-2$ ) in patients undergoing endovascular therapy. ${ }^{17}$ THERAPY (The Randomized, Concurrent Controlled Trial to Assess the Penumbra System's Safety and Effectiveness in the Treatment of Acute Stroke) enrolled only 102 patients before recruitment was halted prematurely because of the positive results of its predecessors. ${ }^{18} \mathrm{~Pa}-$ tients with large artery anterior circulation strokes due to a clot length $>8 \mathrm{~mm}$, who presented within 4.5 hours, were assigned to either IV tPA alone or IV tPA with adjunctive therapy using the Penumbra aspiration device. Preliminary results revealed that more patients were functionally independent ( $\mathrm{mRS} \mathrm{0-2)}$ at 90 days, though this difference was not statistically significant likely due to inadequate patient numbers. THERAPY differed from other trials due to the sole use of the Penumbra aspiration device, and the inclusion of only patients with a large clot burden. We await the formal publication of results from these trials.

\section{Current generation of randomized controlled studies}

After illustrating the safety and recanalization efficacy of thrombectomy in the subgroup of patients with late presentation ( $>8$ hours) strokes and CT or MR evidence of proximal anterior vessel occlusions with viable penumbra, the investigators of the DAWN (DWI/PWI and CTP assessment in the triage of wake-up and late presenting strokes undergoing neurointervention) trial are furthering this hypothesis with a multicenter study aiming to demonstrate improved clinical outcomes at 90 days using the Trevo Retriever with medical management compared to medical management alone. ${ }^{41,42}$ An estimated 500 patients will be randomized, with primary outcomes based on 90 day $\mathrm{mRS}$ scores and mortality.

The PISTE (Pragmatic Ischaemic Stroke Thrombectomy Evaluation) trial aims to randomise 800 patients across multiple centers in the UK, who present within 4.5 hours of symptom onset with a clinically significant neurological deficit (NIHSS $\geq 6$ ) and imaging (CT/MRA/DSA) evidence of a large vessel 
occlusion, to IV thrombolysis alone versus additional mechanical thrombectomy using a variety of devices. ${ }^{43}$ IA therapy is commenced within 6 hours of presentation using an approved device as per the discretion of the neurointerventionalist. The primary outcome measured is again mRS 0-2 at 3 months. Secondary outcomes include full recovery (mRS 0-1), recanalization, safety (ie rates of $\mathrm{ICH}$ ) and mortality.

\section{Future endovascular device development}

Given the success of the Solitaire device in mechanical embolectomy, it currently remains the most popular device used for the treatment of acute ischemic stroke. ${ }^{13}$ However, there are several new devices currently being developed with the aim of offering improved recanalization and safety profiles, with a particular emphasis on minimising distal clot embolization.

\section{Conclusion}

Endovascular intra-arterial therapy improves recanalization rates compared to intravenous thrombolysis. Initial approaches and randomized controlled trials could not demonstrate a corresponding association with improved neurological outcome. However, the development of superior intra-arterial devices, rapid treatment times and increasing availability of sophisticated imaging techniques has resulted in the establishment of intra-arterial therapy as a front line therapy for acute ischaemic stroke.

\section{References}

1. Saver JL, Fonarow GC, Smith EE, Reeves MJ, Grau-Sepulveda MV, Pan W, et al. Time to Treatment With Intravenous Tissue Plasminogen Activator and Outcome From Acute Ischemic Stroke. JAMA 2013;23:2480-2488.

2. Wardlaw JM, Murray V, Berge E, del Zoppo G, Sandercock P, Lindley RL, et al. Recombinant tissue plasminogen activator for acute ischaemic stroke: an updated systematic review and metaanalysis. Lancet 2012;379:2364-2372.

3. Bhatia R, Hill MD, Shobha N, Menon B, Bal S, Kochar P, et al. Low rates of acute recanalization with intravenous recombinant tissue plasminogen activator in ischemic stroke: real-world experience and a call for action. Stroke. 2010;41:2254-2258.

4. Rubiera M, Alvarez-Sabín J, Ribo M, Montaner J, Santamarina E, Arenillas JF, et al. Predictors of early arterial reocclusion after tissue plasminogen activator-induced recanalization in acute ischemic stroke. Stroke 2005;36:1452-1456.

5. Sandercock P, Lindley R, Wardlaw J, Dennis M, Lewis S, Ven- ables G, et al. Third international stroke trial (IST-3) of thrombolysis for acute ischaemic stroke. Trials 2008;9:37.

6. Broderick JP, Palesch YY, Demchuk AM, Yeatts SD, Khatri P, Hill $\mathrm{MD}$, et al. Endovascular therapy after intravenous t-PA versus t-PA alone for stroke. N Engl J Med. 2013;368:893-903.

7. Kidwell CS, Jahan R, Gornbein J, Alger JR, Nenov V, Ajani Z, et al. A trial of imaging selection and endovascular treatment for ischemic stroke. N Engl J Med 2013;368:914-923.

8. Ciccone A, Valvassori L, Nichelatti M, Sgoifo A, Ponzio M, Sterzi R, et al. Endovascular treatment for acute ischemic stroke. $N$ Engl J Med 2013;368:904-913.

9. Saver JL, Jahan R, Levy EI, Jovin TG, Baxter B, Nogueira RG, et al. Solitaire flow restoration device versus the Merci Retriever in patients with acute ischaemic stroke (SWIFT): a randomised, parallel-group, non-inferiority trial. Lancet 2012;380:1241-1249.

10. Nogueira RG, Lutsep HL, Gupta R, Jovin TG, Albers GW, Walker GA, et al. Trevo versus Merci retrievers for thrombectomy revascularisation of large vessel occlusions in acute ischaemic stroke (TREVO 2): a randomised trial. Lancet 2012;380:1231-1240.

11. Rohde S, Haehnel S, Herweh C, Pham M, Stampfl S, Ringleb $\mathrm{PA}$, et al. Mechanical thrombectomy in acute embolic stroke: preliminary results with the revive device. Stroke 2011;42: 2954-2956.

12. Berkhemer OA, Fransen PS, Beumer D, van den Berg LA, Lings$\mathrm{ma} \mathrm{HF}$, Yoo AJ, et al. A randomized trial of intraarterial treatment for acute ischemic stroke. NEngl J Med 2015;372:11-20.

13. Campbell BC, Mitchell PJ, Kleinig TJ, Dewey HM, Churilov L, Yassi N, et al. Endovascular therapy for ischemic stroke with perfusion-imaging selection. NEngl J Med 2015;372:1009-1018.

14. Goyal M, Demchuk AM, Menon BK, Eesa M, Rempel JL, Thornton J, et al. Randomized assessment of rapid endovascular treatment of ischemic stroke. N Engl J Med 2015;372:1019-1030.

15. Saver JL, Goyal M, Bonafe A, Diener HC, Levy EI, Pereira $\mathrm{VM}$, et al. Stent-retriever thrombectomy after intravenous t-PA vs. t-PA alone in stroke. N Engl J Med 2015. doi:10.1056/NEJMoa1415061.

16. Jovin TG, Chamorro A, Cobo E, de Miquel MA, Molina CA, Rovira A, et al. Thrombectomy within 8 hours after symptom onset in ischemic stroke. N Engl J Med 2015. doi:10.1056/ NEJMoa1503780.

17. Bracard S, Ducrocq X, et al. THRACE: Trial and cost effectiveness evaluation of intra-arterial thrombectomy in acute ischemic stroke. In: european stroke organisation (ESO) conference. 2015: Abstract 180.

18. Mocco J, Khatri P, Zaidat O. THERAPY: The randomized, concurrent controlled trial to assess the penumbra system's safety and effectiveness in the treatment of acute stroke. In: european stroke organisation (ESO) conference. 2015: Abstract 82. 
19. The IMS Study Investigators. Combined intravenous and intra-arterial recanalization for acute ischemic stroke: the Interventional Management of Stroke Study. Stroke. 2004;35: 904911.

20. Meyers PM, Schumacher HC, Higashida RT, Barnwell SL, Creager MA, Gupta R, et al. Indications for the performance of intracranial endovascular neurointerventional procedures: a scientific statement from the American Heart Association Council on Cardiovascular Radiology and Intervention, Stroke Council, Council on Cardiovascular Surgery. Circulation 2009; 119:22352249.

21. Del Zoppo GJ, Higashida RT, Furlan AJ, Pessin MS, Rowley HA, Gent M. PROACT: a phase ii randomized trial of recombinant pro-urokinase by direct arterial delivery in acute middle cerebral artery stroke. PROACT investigators. Prolyse in acute cerebral thromboembolism. Stroke 1998;29:4-11.

22. Furlan A, Higashida R, Wechsler L, Gent M, Rowley H, Kase C, et al. Intra-arterial prourokinase for acute ischemic stroke. JAMA 1999;282:2003-2011.

23. Ogawa A, Mori E, Minematsu K, Taki W, Takahashi A, Nemoto $S$, et al. Randomized trial of intraarterial infusion of urokinase within 6 hours of middle cerebral artery stroke: the middle cerebral artery embolism local fibrinolytic intervention trial (MELT) Japan. Stroke 2007;38:2633-2639.

24. Lewandowski CA, Frankel M, Tomsick TA, Broderick J, Frey J, Clark W, et al. Combined intravenous and intra-arterial r-TPA versus intra-arterial therapy of acute ischemic stroke: Emergency Management of Stroke (EMS) Bridging Trial. Stroke 1999; 30:2598-2605.

25. The IMS II Trial Investigators. The interventional management of stroke (IMS) II study. Stroke 2007;38:2127-2135.

26. Mazighi M, Serfaty JM, Labreuche J, Laissy JP, Meseguer E, Lavallée PC, et al. Comparison of intravenous alteplase with a combined intravenous-endovascular approach in patients with stroke and confirmed arterial occlusion (RECANALISE study). Lancet Neurol 2009;8:802-809.

27. Smith WS, Sung G, Saver J, Budzik R, Duckwiler G, Liebeskind DS, et al. Mechanical thrombectomy for acute ischemic stroke: final results of the multi MERCI trial. Stroke 2008;39: 1205-1212.

28. Mourand I, Brunel H, Costalat V, Riquelme C, Lobotesis K, Milhaud D, et al. Mechanical thrombectomy in acute ischemic stroke: catch device. AJNR Am J Neuroradiol 2011;32:13811385.

29. Covidien. Covidien Revascularization Device Receives FDA Clearance. 2012. Available at: http://www.covidien.com/imageServer.aspx/doc245416.pdf? contentID=31741\&contentt ype=application/pdf.
30. Papanagiotou P, Roth C, Walter S, Behnke S, Politi M, Fassbender $\mathrm{K}$, et al. Treatment of acute cerebral artery occlusion with a fully recoverable intracranial stent. Circulation 2010;121: 2605-2606.

31. Natarajan SK, Siddiqui AH, Hopkins LN, Levy EI. Retrievable, detachable stent-platform-based thrombectomy device (Solitaire $^{\mathrm{TM}} \mathrm{FR}$ ) for acute stroke revascularization: first demonstration of feasibility in a canine stroke model. Vasc Dis Manag 2010; $7: 120-125$

32. San Román L, Obach V, Blasco J, Macho J, Lopez A, Urra X, et al. Single-center experience of cerebral artery thrombectomy using the TREVO device in 60 patients with acute ischemic stroke. Stroke 2012;43:1657-1659.

33. Bose A, Henkes H, Alfke K, Reith W, Mayer TE, Berlis A, et al. The penumbra system: a mechanical device for the treatment of acute stroke due to thromboembolism. AJNR Am J Neuroradiol 2008;29:1409-1413.

34. Hernandez E, Goel N, Dougherty KG, Strickman NE, Krajcer Z. Benefits of catheter thrombectomy during carotid stenting: a preliminary study. Tex Heart Inst J 2009;36:404-408.

35. Higashida RT, Furlan AJ, Roberts H, Tomsick T, Connors B, Barr $\mathrm{J}$, et al. Trial design and reporting standards for intra-arterial cerebral thrombolysis for acute ischemic stroke. Stroke 2003;34:e109e137.

36. Frei D, Gerber J, Turk A, McPherson M, HeckD, Hui F, et al. The SPEED study: initial clinical evaluation of the Penumbra novel 054 Reperfusion Catheter. J Neurointerv Surg 2013;5(Suppl 1): i74-i76.

37. Penumbra Pivotal Stroke Trial Investigators. The penumbra pivotal stroke trial: safety and effectiveness of a new generation of mechanical devices for clot removal in intracranial large vessel occlusive. Stroke 2009;40:2761-2768.

38. Tarr R, Hsu D, Kulcsar Z, Bonvin C, Rufenacht D, Alfke K, et al. The POST trial: initial post-market experience of the Penumbra system: revascularization of large vessel occlusion in acute ischemic stroke in the United States and Europe. J Neurointerv Surg 2010;2:341-344.

39. Barber PA, DemchukAM, Zhang J, Buchan AM. Validity and reliability of a quantitative computed tomography score in predicting outcome of hyperacute stroke before thrombolytic therapy. ASPECTS Study Group. Alberta Stroke Programme Early CT Score. Lancet 2000;355:1670-1674.

40. Saver J. Solitaire ${ }^{\mathrm{TM}}$ FR as Primary Treatment for Acute Ischemic Stroke (SWIFT PRIME). Clinicaltrials.gov 2013.

41. Nogueira RG, Liebeskind D, Gupta R, Levy E, Rai A, Barreto A, et al. Preliminary data for the DAWN trial (DWI and CTP assessment in the triage of wake-up and late presenting strokes undergoing neurointervention): imaging based endovascular 
therapy for proximal aneterior circulation occlusions beyond 8 h from last seen well. J Neurointerven Surg 2009; 1:85 (abstract).

42. Jovin TG, Nogueira RG. Trevo and medical management versus medical management alone in wake up and late presenting strokes (DAWN). 2014. Available at: http://clinicaltrials.gov/
ct2/show/study/NCT02142283. Accessed September 28, 2014. 43. Muir K, White P. PISTE (Pragmatic Ischaemic Stroke Thrombectomy Evaluation) trial. 2014. Available at: http://www.gla. ac.uk/media/media_298127_en.pdf. Accessed November 26, 2014. 